DOI: http://dx.doi.org/10.22484/2177-5788.2017v43n2p247-260

\title{
O cinema como vivência dos direitos humanos na escola
}

\author{
Gabriela Machado Ramos de Almeida \\ Ana Maria Acker
}

Resumo: O artigo apresenta uma discussão sobre o cinema como via de contato com a alteridade e se dispõe a pensá-lo como ferramenta pedagógica nas escolas, para além da ilustração de conteúdos didáticos, tomando as imagens como dispositivo que permite sensibilizar estudantes, refinar o seu olhar em relação à comunidade que os cerca e incentivá-los a atuar crítica e criativamente no mundo. A discussão é feita a partir de um relato do projeto de extensão Cine Diversidade, do curso de Jornalismo da Universidade Luterana do Brasil (ULBRA), em Canoas/RS. Realizado em parceria com escolas públicas do município, envolve ações em duas frentes: um cineclube e uma formação teórico-prática em audiovisual centrada no documentário, oferecida a um grupo de 30 alunos do ensino fundamental. As atividades têm como temas transversais os direitos humanos e a diversidade e promovem a abordagem destes assuntos por meio do cinema.

Palavras-chave: Cinema. Educação. Direitos humanos. Diversidade. Comunicação.

\section{The cinema as an experience of human rights in school}

Abstract: The article presents a discussion about cinema as a way of contact with otherness and intends to think about cinema as a pedagogical tool in schools, besides the illustration of didactic contents, considering images as a device that allows to affect students in a sensible way, refine their look in relation to the community that surrounds them and encourage them to act critically and creatively in the world. The discussion is based on a description of Cine Diversidade, an extension project developed by Journalism course of the Lutheran University of Brazil (ULBRA), in Canoas/RS. Held in partnership with public schools in the city, it involves actions on two fronts: a film club and a theoretical-practical formation in audiovisual focused on the documentary, offered to a group of 30 elementary school students. Activities have as their cross-cutting themes human rights and diversity and promote the approach to these issues through film.

Keywords: Cinema. Education. Human rights. Diversity. Communication. 


\section{Introdução}

A discussão sobre diversidade ganhou importância na última década no sistema de ensino brasileiro em função das Leis 10639/2003 e 11645/2008, que estabelecem a obrigatoriedade do ensino de História e Cultura Afro-brasileira e Indígena na Educação Básica, bem como em função das Diretrizes Nacionais para a Educação em Direitos Humanos. Na educação básica, especificamente, as Diretrizes Curriculares Nacionais, Brasil (2013), afirmam o direito à diferença de modo tão fundamental quanto aos direitos civis, políticos e sociais. Isso significa que há uma clara tentativa, no nível das políticas públicas que regem a educação no país, de promover o respeito à diferença por meio do que se considera uma "educação multicultural" (BRASIL, 2013, p. 105) ${ }^{1}$. Essas medidas promoveram ações de valorização das questões relativas a temas como raça, etnia e direitos humanos nas escolas. No entanto, apesar de toda a discussão que se tem sobre estes assuntos - inclusive a respeito do pleno cumprimento das leis - pouco se sabe, de forma sistematizada, sobre a percepção dos próprios estudantes em relação a estes temas.

Para dar vazão a estes assuntos no âmbito universitário e também na comunidade escolar de Canoas, município onde está situada a Universidade Luterana do Brasil (ULBRA), o projeto de extensão Cine Diversidade foi criado pela coordenação do curso de Jornalismo da instituição com dois objetivos principais: utilizar o cinema para intensificar a discussão sobre direitos humanos, diversidade e diferença nas escolas e na própria universidade, e proporcionar aos estudantes da rede pública de ensino da cidade a oportunidade de apresentar sua visão por meio da realização de documentários com este mesmo recorte temático transversal do projeto. Para além da defesa do cinema como ferramenta pedagógica, que serve à ilustração de conteúdos didáticos, o projeto pensa o audiovisual enquanto dispositivo que permite sensibilizar os estudantes oferecendo-lhes repertório, refinar o seu olhar em relação à comunidade que os cerca e incentivá-los a atuar crítica e criativamente no mundo.

Parte-se de um entendimento, conforme Migliorin (2015, p. 181), de que uma pedagogia "é necessariamente uma construção individual e coletiva, que trabalha as possibilidades pessoais dos indivíduos e seus engajamentos com a comunidade, com a diferença, com a

\footnotetext{
${ }^{1} \mathrm{O}$ texto diz que o direito à diferença "busca garantir que, em nome da igualdade, não se desconsiderem as diferenças culturais, de cor/raça/etnia, gênero, idade, orientação sexual, entre outras. Em decorrência, espera-se que a escola esteja atenta a essas diferenças, a fim de que em torno delas não se construam mecanismos de exclusão que impossibilitem a concretização do direito à educação, que é um direito de todos" (BRASIL, 2013, p. 105).
} 
alteridade" e também de uma apropriação da noção de partilha do sensível, que segundo Rancière (2005), permite pensar, a partir da ideia de um "comum compartilhado", na potência do cinema, no nível da sua fruição e também da produção, na constituição de experiências sensíveis de ordem ao mesmo tempo ética, estética e política.

\section{Sobre a criação do Cine Diversidade}

A criação do projeto Cine Diversidade se deu em 2015 e partir de uma parceria entre o curso de Jornalismo e o Núcleo de Estudos Afro-Brasileiros e Indígenas da ULBRA (NEABI), formado em 2014, integrado ao projeto institucional de fomentar e articular atividades de ensino, extensão e pesquisa sobre a história e a cultura afro-brasileira e indígena. O NEABI conta com duas linhas de atuação: História, Patrimônio Cultural e Identidades e Midiatização e Culturas Contemporâneas (o projeto se vincula a esta última).

O Cine Diversidade se desdobra em duas frentes: 1) Cineclube nas escolas e 2) Registros sobre direitos humanos e diversidade nas escolas. Executado por professoras do curso de Jornalismo da ULBRA, em parceria com escolas públicas de Canoas, o projeto conta com um cineclube que promove sessões semanais de filmes brasileiros nas escolas - a frente $1-\mathrm{e}$ também com uma formação teórico-prática em audiovisual, centrada no cinema documentário, oferecida gratuitamente na ULBRA a um grupo de 30 alunos dos anos finais do ensino fundamental das mesmas escolas (que são participantes voluntários) - a frente 2. Também participam, na condição de bolsistas e voluntários, alunos de Jornalismo da Universidade.

Ambas as atividades têm como temas transversais os direitos humanos e a diversidade e promovem a abordagem destes assuntos por meio do cinema, a partir da instrumentalização dos alunos para a realização de documentários e também da formação de repertório que valoriza o cinema brasileiro com filmes contemporâneos que abordam questões étnico-raciais, violência, gênero, sexualidade e tolerância religiosa, entre outros temas. As Diretrizes Curriculares Nacionais consideram que a adoção de uma perspectiva multicultural em relação aos currículos escolares contribui para uma sociedade mais democrática e solidária:

\footnotetext{
Entende-se que os conhecimentos comuns do currículo criam a possibilidade de dar voz a diferentes grupos como os negros, indígenas, mulheres, crianças e adolescentes, homossexuais, pessoas com deficiência. Mais ainda: o conhecimento de valores, crenças, modos de vida de grupos sobre os quais os currículos se calaram durante uma centena de anos sob o manto da igualdade formal propicia desenvolver empatia e respeito pelo outro, pelo que é diferente de nós, pelos alunos na sua diversidade étnica, regional, social, individual e grupal, e leva a conhecer as razões dos conflitos que se
} 
escondem por trás dos preconceitos e discriminações que alimentam as desigualdades sociais, étnico-raciais, de gênero e diversidade sexual, das pessoas com deficiência e outras, assim como os processos de dominação que têm, historicamente, reservado a poucos o direto de aprender, que é de todos. (BRASIL, 2013, p. 115).

O projeto propõe, assim, trocas de vários níveis entre a universidade e a comunidade em que está inserida, valorizando as relações entre diversos atores (alunos das escolas e da universidade, professores das escolas e da universidade e comunidade universitária que vivencia atividades do projeto abertas ao público). A proposta tem caráter comunitário e se baseia, em linhas gerais, na análise e produção de conteúdos midiáticos - filmes - que permitem a todos os envolvidos pensar o mundo que os cerca por meio das imagens.

\section{Pensando e inventando mundos com o cinema na escola}

O Cine Diversidade pensa o cinema como uma via de contato com a alteridade por meio de experiências diversas. Os filmes selecionados para compor o trabalho de formação do repertório dos estudantes participantes, portanto, são discutidos em seus aspectos estéticos e narrativos como forma de estimular o debate entre os alunos. O projeto começou com duas escolas parceiras de Canoas (E.E.E.F. Vicente Freire e Vasco da Gama), com uma turma de 15 alunos que participaram em 2015 das atividades realizadas na ULBRA (a frente 1 - formação teórico-prática em audiovisual). Em 2016, o Cine Diversidade expandiu-se, incorporou o cineclube, passou a ter mais uma escola agregada (Colégio Estadual Miguel Lampert) e atualmente conta com 30 participantes das três instituições de ensino que recebem a formação, além de um público em torno de 25 alunos a cada sessão promovida pelo cineclube nas escolas. A partir de 2017, mais uma escola se tornou parceira e o cineclube passou a acontecer exclusivamente nela (a Escola Municipal de Ensino Fundamental Paulo Freire, também de Canoas).

\section{Cineclube nas escolas}

O principal objetivo do Cineclube nas escolas é a exibição de filmes brasileiros, sobretudo documentários, com temáticas relacionadas aos direitos humanos e diversidade para alunos das séries finais do ensino fundamental $-6^{\circ}$ ao $9^{\circ}$ ano. A atividade é coordenada pela professora Ana Maria Acker, responsável pela curadoria do cineclube, pelo agendamento das sessões e pela mediação dos debates. 
O uso do cinema na educação tem se mostrado um instrumento pedagógico importante diante das transformações tecnológicas e da disseminação das imagens como aspecto inevitável da experiência dos indivíduos no mundo nas últimas décadas. Segundo Marília Franco (2010), é necessário que o cinema seja experimentado como parte do cotidiano escolar, e não apenas como ilustração de temas ou conteúdo específicos. Além disso, pode estimular trocas, possibilidades de pensamento diversas e a criatividade por meio da linguagem artística:

\begin{abstract}
A linguagem científica tem perfil analítico, descritivo, minucioso, metódico, de rigoroso vínculo com o real, procurando responder às suas demandas. Tem como finalidade mobilizar as nossas competências cognitivas de racionalidade. A linguagem artística, por outro lado, é, em todas as formas de expressão estética, uma linguagem de síntese, que resume, que reconfigura, que desconfigura, que mais indaga do que responde, que dialoga com o sonho, o devaneio e a incerteza. Busca, seja nas formas mais tradicionais como nas mais experimentais, mobilizar nossa percepção, sensibilidade e adesão afetiva, emocional, intuitiva. (FRANCO, 2010, p. 12).
\end{abstract}

Desta forma, o uso sistemático do cinema em sala de aula é parte efetiva do processo cognitivo dos alunos. Os bens simbólicos gerados pela cultura midiática são responsáveis por mediar, em certos aspectos, a relação das pessoas com o meio em que vivem. Assim, discutir questões relevantes e atuais através de filmes é uma ferramenta que pode ser cada vez mais explorada pela educação em todos os níveis.

A atuação do Cineclube nas escolas propõe, então, instrumentalizar alunos e professores de Canoas para a análise de produtos midiáticos, bem como fomentar o pensamento sobre o papel dos bens simbólicos na discussão das representações produzidas pela cultura popular massiva. Uma lista prévia de filmes foi apresentada às escolas participantes do projeto, que aprovaram as sugestões e reforçaram a necessidade de estímulo ao pensamento crítico nos alunos.

Em um primeiro momento, os filmes foram exibidos integralmente às turmas, seguidos por debate. As questões se aprofundaram a respeito da temática abordada; detalhes e dúvidas sobre as narrativas surgiram, bem como indagações de cunho estético, sobre o uso da câmera, por exemplo. É importante ressaltar que, mesmo pouco habituados aos documentários, os estudantes mostraram-se instigados pelas produções - não houve caso de desinteresse durante as exibições, ou de estudantes se retirando da sala de vídeo.

A única alteração no formato ocorreu na divisão dos filmes, que passaram a ser exibidos em duas partes. Assim, uma mesma turma fica envolvida com a obra por duas semanas. Uma parte é apresentada, faz-se um debate inicial; e na semana seguinte, a sessão é finalizada com o 
fechamento do debate (Fig.1). Com essa mudança, identificou-se que os alunos interagem mais com os filmes, trazem questões a respeito e conseguem compreender a obra numa dimensão artística, social e política.

Figura 1 - Debate posterior à sessão na Escola Vasco da Gama

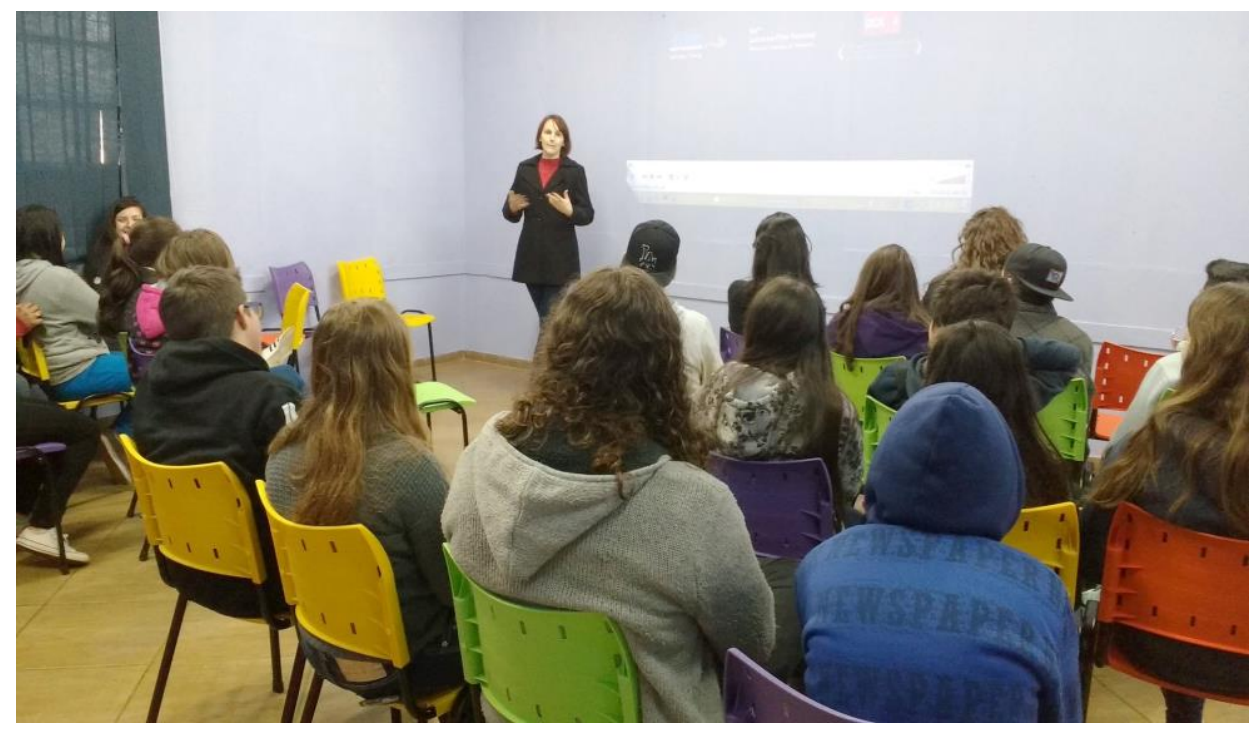

Fonte: Reprodução de fotografia produzida por Julia Renz.

Na Escola Paulo Freire, a dinâmica foi mantida, com a diferença de que há uma prioridade para curtas-metragens, em função dos horários dos alunos (Fig. 2). As exibições de longas em duas etapas ocorrem, porém são mais raras. Por meio da abordagem dos direitos humanos, consegue-se, além do conhecimento, experimentar o contato com o outro:

Ela, a alteridade, nos ajuda a nos vermos no outro, a compreender as semelhanças e a aceitar as diferenças. Ela é o fundamento da convivência, da colaboração, da capacidade de construir coletivamente. Desenvolver a noção que ela nos oferece é um desejo teórico de todos, mas também uma prática revolucionária depois de, pelo menos, um século de exercício estimulado por competitividade e individualismo, de que não estão imunes os modelos escolares ainda em execução no país. (FRANCO, 2010, p. 15). 
Figura 2 - Exibição de curta sobre a questão indígena na Escola Paulo Freire

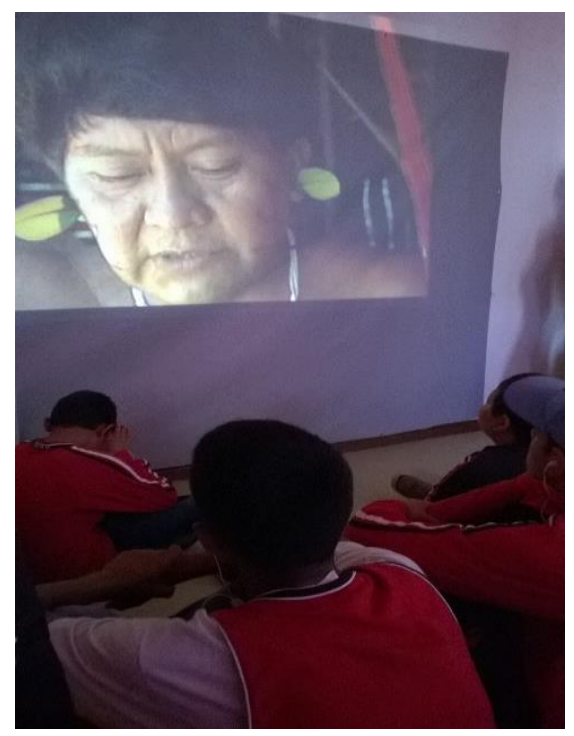

Fonte: Reprodução de fotografia elaborada por Ana Acker.

Esse encontro com o outro não é apenas uma possibilidade de conhecimento, de saber sobre esse outro, mas de viver uma experiência em relação a ele, conforme salienta Migliorin (2010, p. 5):

\begin{abstract}
O cinema não se encontra na escola para ensinar algo a quem não sabe, mas para inventar espaços de compartilhamento e invenção coletiva, colocando diversas idades e vivências diante das potências sensíveis de um filme. Digamos assim: a democracia é o acontecimento que provoca o encontro não organizado de diversas inteligências, uma ação em si emancipatória.
\end{abstract}

Ainda conforme Migliorin (2010), o audiovisual precisa desestabilizar, gerar o incômodo em certos momentos, ser recorrente no ambiente escolar para de fato constituir uma vivência. Nesses dois anos de projeto, percebemos a reação dos alunos, como nesses comentários de dois estudantes da Escola Vasco da Gama, sobre o documentário Juízo, realizado em 2007, por Maria Augusta Ramos, que mostra a situação de jovens em conflito com a lei no Rio de Janeiro. Uma aluna do $9^{\circ}$ ano, de 14 anos, opina: "Vemos coisas bem diferentes da nossa realidade. Como nesse filme agora é estranho ver isso, pois nunca aconteceu com ninguém perto de mim. É meio que um choque de realidade. Eu acho legal essa noção do que acontece." (informação verbal) ${ }^{2}$

\footnotetext{
${ }^{2}$ Depoimentos gravados com os estudantes em junho de 2016, pelo autor.
} 
Outro aluno, de 16 anos, do $9^{\circ}$ ano, em opinião semelhante considera a visualização do filme um choque de realidade:

Tu não esperas que isso vá ocorrer com alguma pessoa ou até mesmo contigo. É bom tu saberes o que acontece, o que essas pessoas passam, de realmente entender o lado delas. Na condição que estamos, não imaginamos que isso vá acontecer conosco, termos que roubar porque não podemos comprar o leite para os filhos. É bom saber disso, porque pode ocorrer com qualquer pessoa, e saber o que se passa, como no centro de ressocialização deles, é uma coisa horrível de presenciar e ver alguém naquela situação. (informação verbal). ${ }^{3}$

Esses relatos já dão indícios de que o olhar em relação ao outro está sendo tensionado e certas percepções têm se desestabilizado, entre elas a da complexidade do mundo e de seus desafios para além dos conteúdos tradicionais do currículo do ensino fundamental. Outro desdobramento é a oficina de formação audiovisual que está sendo realizada na Paulo Freire (Fig. 3), em paralelo ao cineclube. A demanda partiu da professora de Artes da escola, Janaí Pedroso. Os alunos tiveram aulas sobre linguagem audiovisual e já finalizam um curta documental sobre o tema "felicidade na escola". As gravações e a ideia de roteiro foram feitas pelos estudantes com o auxílio das professoras.

Figura 3 - Alunos em atividade durante a oficina da Escola Paulo Freire

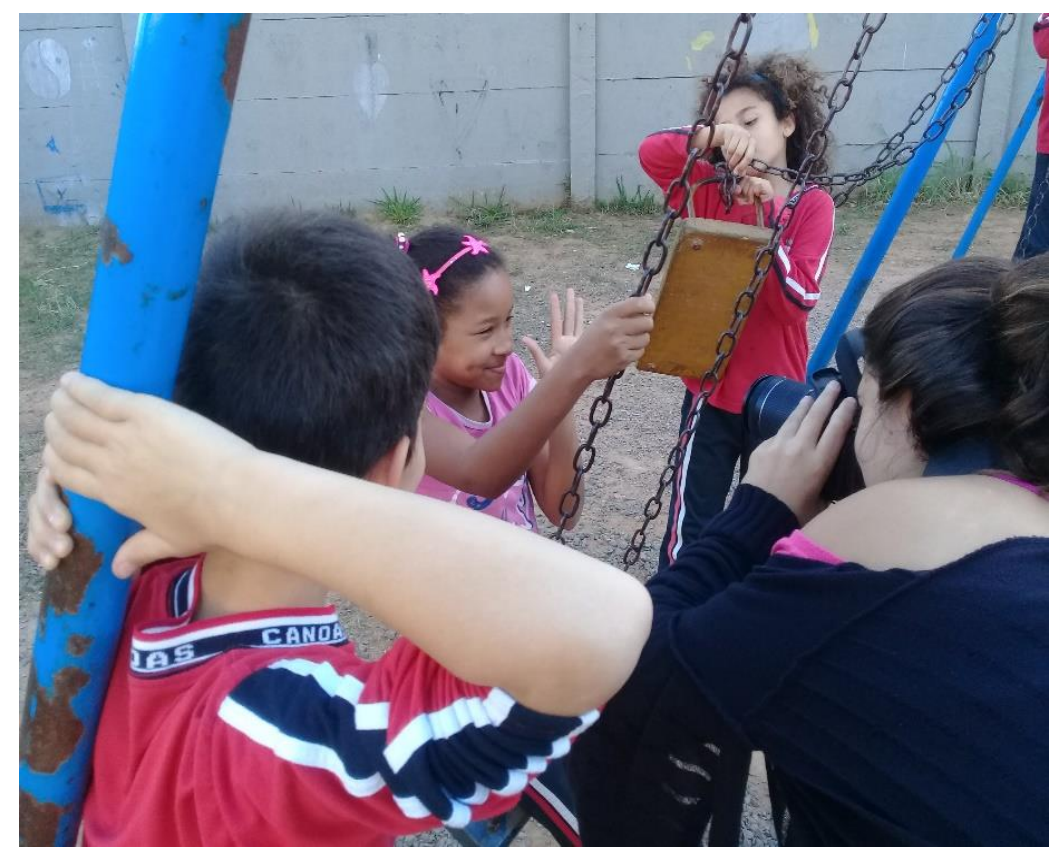

Fonte: Reprodução de fotografia elaborada por Ana Maria Acker

\footnotetext{
${ }^{3}$ Depoimentos gravados com os estudantes em junho de 2016, pelo autor.
} 
A noção de alteridade é um passo importante na consolidação de uma educação sólida para a valorização dos direitos humanos e diversidade na sociedade brasileira e essa ideia tem sido desenvolvida na Escola Paulo Freire por meio do audiovisual.

\section{Registros audiovisuais sobre direitos humanos e diversidade nas escolas}

A outra frente do projeto Cine Diversidade, chamada Registros audiovisuais sobre direitos humanos e diversidade nas escolas, visa oferecer um curso que funciona como base para que os alunos produzam seus próprios documentários, abordando temas que se encaixem no escopo temático do projeto.

A formação que os estudantes recebem ocorre em aulas semanais, realizadas nas tardes de quinta-feira, e tem duração de um ano letivo (totalizando 120 horas/aula). Os alunos que participam da formação com frequência superior a 75\% das aulas são certificados no final do curso, em uma formatura simbólica em que também são exibidos os documentários resultantes do projeto. O envolvimento dos estudantes se dá de forma espontânea e não-remunerada, e até o momento o projeto pode atender a todos os que manifestaram interesse em participar da formação nas visitas de apresentação do projeto e prospecção de alunos que foram feitas nas escolas parceiras.

As atividades são realizadas nas dependências do curso de Jornalismo da ULBRA, especialmente nos laboratórios do Núcleo de Produção Audiovisual da Universidade (nos estúdios de televisão, fotografia e som e nas ilhas de edição de vídeo). As aulas, de cunho teórico-prático, são ministradas pela professora Gabriela Machado Ramos de Almeida. Após uma formação inicial em linguagem e estética do audiovisual, o grupo passa à prática, com a realização de exercícios de fotografia, escrita de roteiros curtos e gravação de cenas; noções de direção, enquadramentos e movimentos de câmera; captação de som e edição de vídeo.

Em paralelo, as questões relativas aos direitos humanos e à diversidade são abordadas principalmente no trabalho de formação de repertório em cinema documentário, baseado em Freire (2012) e Lins e Mesquita (2008) e centrado na produção brasileira. A exibição e discussão de um extenso conjunto de filmes ao longo das aulas permite trazer à discussão assuntos como racismo, violência de gênero, a condição da mulher, homofobia, migrações e religião (Fig. 4). 
Figura 4 - Registros de atividades práticas realizadas pelos participantes do Cine Diversidade

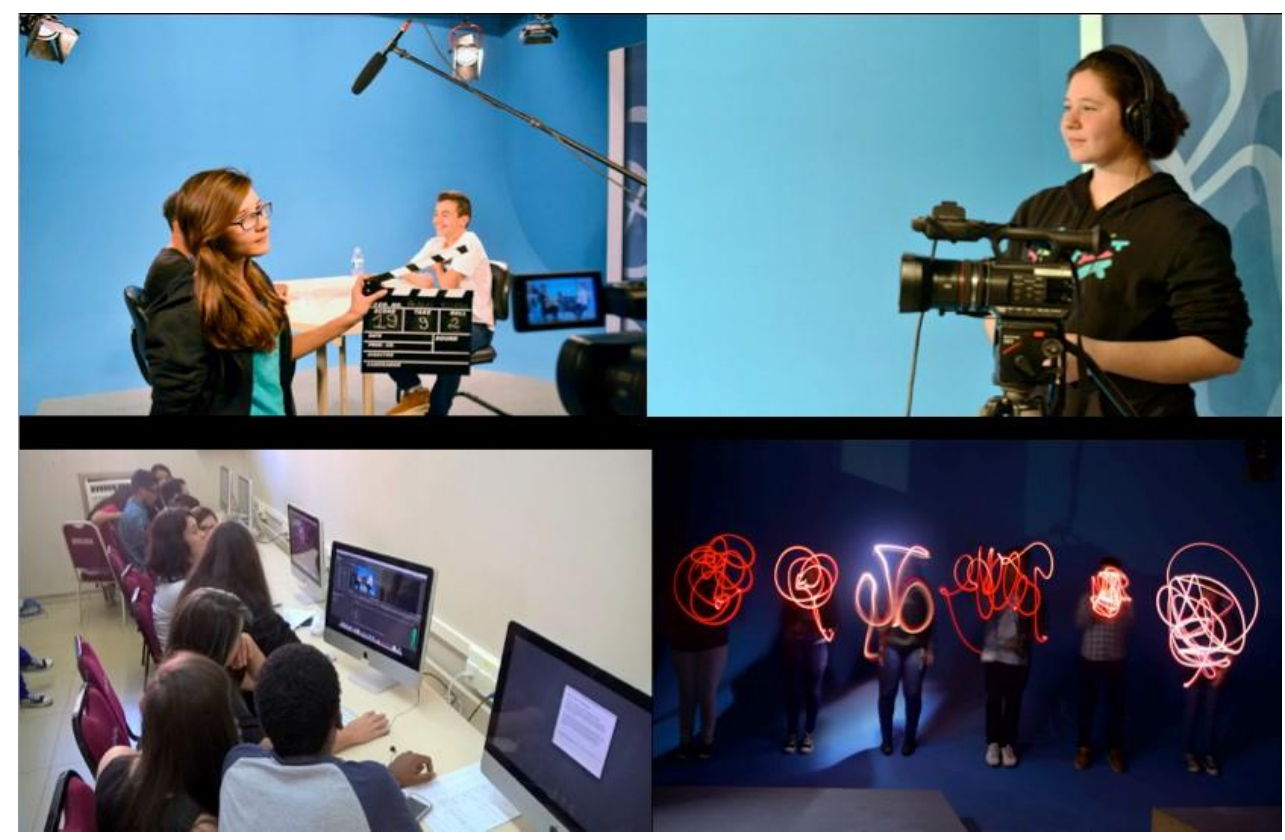

Fonte: Painel com reprodução de fotografias por Augusto Bozzetti.

A título de exemplo, mencionamos o documentário Doméstica, de Gabriel Mascaro, realizado em 2012, com imagens e entrevistas inteiramente produzidas por adolescentes de sete diferentes famílias residentes em diversas capitais, que filmaram as empregadas domésticas que trabalham em suas casas e repassaram o material bruto ao cineasta. $\mathrm{O}$ debate em torno do filme se alongou por duas semanas e promoveu nos alunos uma sensibilização sobre aspectos relativos à condição da mulher negra no Brasil no presente.

Parte da inspiração para execução de ambas as frentes do Cine Diversidade vem da experiência Inventar com a diferença, projeto de abrangência muito maior porém com propósito semelhante, desenvolvido ao longo de dois anos, entre 2013 e 2015, com 3 mil alunos de 234 escolas brasileiras. Dele resulta o livro Inevitavelmente cinema: educação, política e mafuá (2015), escrito por Migliorin, coordenador do projeto, que se propôs a pensar politicamente o encontro entre cinema e educação. Nas palavras de Migliorin (2015, p. 181):

Pensemos em uma pedagogia não como uma forma de ensinar, mas como uma relação entre múltiplos atores em que a constituição de sujeitos e comunidades está em questão. Como reiterou Dewey (2004), tantas vezes, a educação não é preparação para a vida, mas a vida mesmo. O que não é diferente das questões ligadas aos direitos humanos. Certa vez um colega nos disse: “Com esse projeto é a primeira vez que os estudantes estão tendo contato com os direitos humanos". Profundo engano. Desde que nasceram estão tendo contato com os direitos humanos, com a vida - os direitos humanos são transversais a tudo. 
É possível retornar a Rancière (2005) e à noção de partilha do sensível para pensar na potência do cinema como instrumento de contato com a diferença. Para o autor, é fundamental considerar como os indivíduos tomam parte nesta partilha de um "comum compartilhado", uma vez que há sempre uma forma de partilha, anterior a este "tomar parte", que determina mesmo os que tomam parte e de que modo. Ou seja, as condições de acesso ao sensível não são universais e existem mecanismos que definem o que Rancière (2005) chama de competências e incompetências para o comum: "A política ocupa-se do que se vê e do que se pode dizer sobre o que é visto, de quem tem competência para ver e qualidade para dizer, das propriedades do espaço e dos possíveis do tempo" (RANCIÈRE, 2005, p. 16).

No caso do Cine Diversidade, isso diz respeito à possibilidade dos alunos de ocuparem um outro lugar na partilha do sensível - aqui, especificamente, a produção de bens simbólicos - a partir do momento em que passam a ser produtores de discursos e inventam mundos com o cinema, vivenciando experiências que se constituem, ao mesmo tempo, como éticas, estéticas e políticas e que convocam a alteridade de diversas maneiras: na maneira de lidar com o outro, de ouvi-lo, de representá-lo. É possível pensar no cinema como mecanismo capaz não apenas de sensibilizar mas, conforme Rancière (2012), também emancipar. A emancipação "começa quando se questiona a oposição entre olhar e agir, quando se compreende que as evidências que assim estruturam as relações do dizer, do ver e do fazer pertencem à estrutura de dominação e sujeição" (RANCIÈRE, 2005, p. 17).

\section{Alguns resultados}

O projeto proporcionou a instrumentalização dos alunos participantes para a análise e realização de produtos audiovisuais, além de incentivar o exercício de um olhar crítico em relação aos conteúdos midiáticos, de forma mais ampla, e a sua sensibilização quanto a questões relativas aos direitos humanos e à diversidade. Este resultado se estende ainda aos estudantes de Jornalismo da Universidade, que participam do projeto na condição de bolsistas e voluntários.

O trabalho conjunto de formação de repertório, debates e exercícios práticos possibilitou que os estudantes propusessem, em 2015 e 2016, a realização de documentários sobre a violência contra a mulher, homofobia, bullying e haters na internet ${ }^{4}$.

\footnotetext{
${ }^{4}$ Os vídeos da edição de 2017 do projeto ainda estão em produção e por este motivo não serão descritos aqui. 
A título de exemplo, vale detalhar um pouco da experiência de produção de um documentário de uma das participantes do projeto. Intitulado Sempre alerta para a violência contra a mulher (Fig. 5), o vídeo tem 18 minutos de duração em sua versão final e reúne depoimentos de uma adolescente de 16 anos, vítima de violência física, psicológica, sexual e moral por parte de um ex-namorado, uma assistente social que trabalha no atendimento a mulheres vítimas de violência e da própria realizadora, que expõe suas motivações para a realização do documentário. O título remete ao lema dos Escoteiros, grupo do qual a realizadora faz parte e, segundo seus relatos, no qual são constantes manifestações de machismo e assédio às meninas. A constatação deste cenário foi o que motivou a produção do documentário (a aluna não relata casos de violência de gênero contra si mesma ou alguém de sua família). A própria estudante ficou responsável pela pesquisa de personagens, pelo agendamento das entrevistas necessárias à realização do documentário e pela montagem do material, sob supervisão de professores e monitores envolvidos no projeto.

Figura 5 - Frame do documentário Sempre alerta para a violência contra a mulher

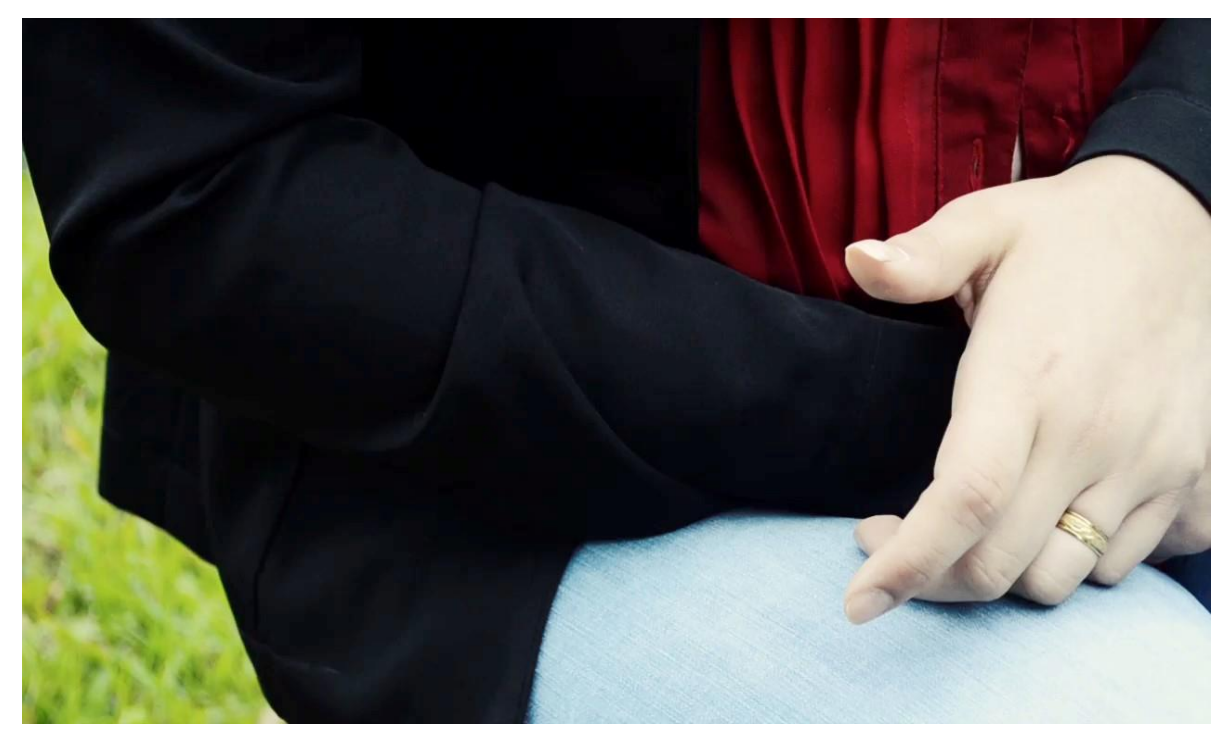

Fonte: Impressão de tela do documentário.

Como atividades complementares ao projeto Cine Diversidade, são promovidos eventos gratuitos abertos à comunidade da ULBRA e também ao público externo, como o curso de extensão em Cinemas Africanos, a Mostra Cinemas Africanos e as sessões de exibição dos filmes Que horas ela volta? (Anna Muylaert, 2015); Hoje eu quero voltar sozinho (Daniel Ribeiro, 2014) e O ano em que meus pais saíram de férias (Cao Hamburguer, 2006). 
O curso de extensão e a mostra Cinemas Africanos foram promovidos em parceria com o crítico de cinema, pesquisador e jornalista Pedro Henrique Gomes. O público total foi de cerca de 400 pessoas, incluindo alunos e professores dos cursos de Comunicação Social da ULBRA, os estudantes de ensino fundamental atendidos pelo projeto de extensão, professores das escolas e participantes externos, oriundos de diversos municípios da região metropolitana de Porto Alegre, como Canoas, São Leopoldo, Novo Hamburgo, Guaíba, Cachoeirinha, Alvorada, Esteio, Montenegro, Gravataí, Viamão e Nova Santa Rita.

A mostra contou com a exibição de cinco filmes produzidos em diferentes décadas e países africanos (A Negra de..., Ousmane Sembéne, Senegal, de 1966; A Viagem da Hiena, Djibril Diop Mambety, Senegal, de 1973; A Luz, Souleymane Cissé, Mali, de 1987; Yaaba, Idrissa Ouedraogo, Burkina Faso, de 1989; Na cidade vazia, Maria Joao Ganga, Angola, de 2004). As exibições dos filmes, que ocorreram ao longo de cinco noites, foram sucedidas por um debate posterior a cada sessão, com críticos de cinema e pesquisadores africanistas, que discutiram as obras a partir dos aspectos estéticos e temáticos, totalizando dez debatedores convidados.

\section{Considerações finais}

As duas frentes de atuação do projeto Cine Diversidade corroboram o entendimento do cinema como instrumento pedagógico agregador no exercício de uma educação permanente para os direitos humanos e a diversidade. O reconhecimento da alteridade por meio da experiência sensível com o audiovisual constitui-se estratégia pertinente na construção de uma relação com o outro e o mundo que se entrelace com as demais temáticas trabalhadas em sala de aula nas disciplinas.

$\mathrm{O}$ ato de ver imagens diferentes das habituais no cotidiano dos alunos tem auxiliado no aprendizado de narrativas e propostas estéticas audiovisuais diversas, instigantes. Essas atividades já alcançam uma expansão do repertório dos estudantes, conforme identificado nos dois depoimentos expostos neste artigo.

Tal repertório se transforma ainda mais efetivamente na manipulação de equipamentos tecnológicos e softwares de edição nas oficinas de audiovisual. As produções assistidas em sala de aula são ressignificadas e inspiradoras na realização de exercícios práticos, ou seja, um projeto complementa o outro. 
O Cine Diversidade estabelece, assim, um elo entre a universidade e a comunidade que a cerca, levando os alunos de graduação para um contato com instituições de ensino, fazendoos reconhecer a dimensão cidadã e a necessidade de compartilhamento do que é estudado no curso de Jornalismo. Em caminho parecido, os professores dessas escolas têm a oportunidade de se aprofundar em estratégias variadas de trato com o audiovisual em sala de aula, encarandoo como uma vivência pedagógica que pode se desenvolver em múltiplos desdobramentos em todas as áreas do conhecimento.

\section{Referências}

BRASIL. Ministério da Educação. Secretaria de Educação Básica. Diretoria de Currículos e Educação Integral. Diretrizes Curriculares Nacionais Gerais da Educação Básica. Brasília, 2013. Disponível em: <http://portal.mec.gov.br/docman/julho2013-pdf/13677diretrizes-educacao-basica-2013-pdf/file>. Acesso em: 13 jun. 2016.

FRANCO, Marilia. Hipótese-cinema: múltiplos diálogos. Revista Contemporânea de Educação, Rio de Janeiro, v. 5, n. 9, 2010. Disponível em:

<http://www.educacao.ufrj.br/artigos/n9/2_hipotese_cinema_e_seus_multiplos_dialogos_8_a _3.pdf >. Acesso em: 5 jun. 2017.

FREIRE, Marcius. Documentário: ética, estética e formas de representação. São Paulo: Annablume, 2012.

LINS, Consuelo; MESQUITA, Cláudia. Filmar o real: sobre o documentário brasileiro contemporâneo. Rio de Janeiro: Zahar, 2008.

MIGLIORIN, Cezar. Cinema e escola, sob o risco da democracia. Revista Contemporânea de Educação, Rio de Janeiro, v. 5, n. 9, 2010. Disponível em:

<http://www.fe.ufrj.br/artigos/n9/9_posfacio_cinema_e_escola_104_a_110.pdf>. Acesso em: 05 jun. 17.

MIGLIORIN, Cezar. Inevitavelmente cinema: educação, política e mafuá. Rio de Janeiro: Beco do Azougue, 2015.

RANCIÈRE, Jacques. A partilha do sensível: estética e política. São Paulo: Editora 34, 2005.

RANCIERE, Jacques. O espectador emancipado. São Paulo: WMF Martins Fontes, 2012.

\footnotetext{
Gabriela Machado Ramos de Almeida - Universidade Luterana do Brasil (ULBRA) | Canoas-RS | Brasil. E-mail: gabriela.mralmeida@gmail.com

Ana Maria Acker - Universidade Luterana do Brasil (ULBRA)

| Canoas-RS | Brasil. E-mail: ana_acker@yahoo.com.br
} 